\title{
The Bellamy challenge: it's about time
}

\author{
Geoffrey P Dobson, ${ }^{1}$ H L Letson, ${ }^{1}$ D Tadaki ${ }^{1,2}$
}

\begin{abstract}
In 1984, Col. Ronald Bellamy launched a worldwide challenge to develop a new resuscitation fluid to aid survival after catastrophic blood loss on the battlefield. In 1996, after careful compromise among need, cube weight and efficacy, the US military and later coalition forces adopted $6 \%$ hetastarch (HES) fluids for early resuscitation. In the intervening years, evidence has amassed indicating that the HES fluids may not be safe, and in June 2013 the US Food and Drug Administration issued a warning that HES solutions should not be used to treat patients with hypovolaemia or the critically ill. We review the unique challenges of early battlefield resuscitation, why the 'Bellamy challenge' remains open and discuss a number of forward-looking strategies that may help to solve the problem. The first two pillars of resuscitation that we believe have not been adequately addressed are rescuing and stabilising the heart (and brain) and the vascular system. The 'ideal' resuscitation fluid needs to nurture the heart and body slowly back to health, and not 'shock' it a second time with unnatural colloids or large volumes of unphysiological saline-based solutions.
\end{abstract}

\section{THE UNMET NEED}

The wars in Afghanistan (2001-present) and Iraq (2003-2009) have resulted in the highest rates of combat casualties for the US and coalition forces since the Vietnam conflict, and deaths from close proximity blast injury patterns are the most common. ${ }^{12}$ Catastrophic haemorrhage is responsible for up to $50 \%$ of trauma deaths on the battlefield, and up to $20 \%$ of these may be salvageable. ${ }^{3}$ In the civilian setting, haemorrhage is responsible for $30 \%-40 \%$ of the 5.8 million trauma deaths globally each year, ${ }^{4}$ with a third to a half occurring in the pre-hospital environment. $^{5}{ }^{6}$ Haemorrhagic shock arises from insufficient cardiac output leading to

\footnotetext{
${ }^{1}$ Department of Physiology and Pharmacology, Heart and Trauma Research Laboratory, James Cook University, Townsville, Queensland, Australia; ${ }^{2}$ Department of Regenerative Medicine, Naval Medical Research Center, Silver Spring, Maryland, USA

Correspondence to Prof Geoffrey P Dobson, Department of Physiology and Pharmacology, Heart and Trauma Research Laboratory, James Cook University, Queensland 4811, Australia; geoffrey.dobson@jcu.edu. au
}

systemic hypotension, widespread tissue hypoperfusion, ischaemia and hypoxia, inflammation and coagulopathy. ${ }^{7}$ Its severity will depend upon the volume of blood lost, the duration of shock and on the ability of the heart and body to compensate with the blood remaining in the circulation. $^{8}$ Shock is what John Collins Warren aptly called in the late 1800s ' $a$ momentary pause in the act of death'.'

In a 1984 landmark paper, 'The causes of death in conventional land warfare: implications for combat casualty care research', Colonel Ronald Bellamy launched a global challenge to develop a new resuscitation fluid to decrease preventable combat death following severe to massive blood loss ${ }^{3}$ (Figure 1). Today, despite advances in blood control technologies such as tourniquets and haemostatic bandages, 6 the 'Bellamy challenge' remains wide open. Indeed, many of fluids available today, including those solutions containing hetastarch (HES), may negatively impact on the resuscitation outcome by promoting cardiovascular instability, inflammation and coagulopathy, and increase the likelihood of widespread ischaemia, infection and multiple organ failure. . $^{5-7} 10-14$

This article is not an in-depth analysis of current resuscitation fluids but rather a general examination of why the Bellamy challenge has remained elusive for 30 years, the clinical reasons why HES was chosen for far forward resuscitation and the evidence amassing against their continued use. Last, we will review the two pillars of resuscitation that we believe have not been adequately addressed in the Bellamy challenge and suggest a number of forward-looking strategies that may help solve the problem. This is an important topic as future conflicts may require longer evacuation times and ultra-small-volume solutions for hypotensive resuscitation to rescue and stabilise the critically wounded.

\section{IT'S ABOUT BUYING TIME!}

After catastrophic injury, the new enemy is time. Buying biological time is the ultimate goal of resuscitation on the battlefield or in the pre-hospital civilian environment. The 'Golden Hour' no longer exists-the combat medic has seconds to minutes to control bleeding in what is called the Platinum 5 or $10 \mathrm{~min}$.

Since $90 \%$ of combat deaths occur before the casualty reaches a medical treatment facility, ${ }^{3}$ in 1993 the US Naval Special Warfare Command, in response to the Bellamy challenge, commissioned the Institute of Medicine for an independent assessment. ${ }^{15}$ This culminated in the first Tactical Combat Casualty Care (TCCC) document, which was published as guidelines in 1996 and used by special forces, medics and parachuting rescue personnel. ${ }^{1617}$

The principle mandate of TCCC guidelines was and remains a 'plan of care' or 'damage control' from the point of injury through to evacuation and definitive care (damage control surgery). The guidelines have three life-saving time windows (Box 1) and have been adopted by most advanced Western armies and in some leading trauma centres around the world. 7151920

Despite its many successes, and numerous Defense Advanced Research Projects Agency and other 'surviving blood loss' programmes, the development of a resuscitation fluid that optimally rescues and stabilises the cardiovascular system (and brain) following catastrophic blood loss has been elusive.

\section{HES FLUID RESUSCITATION: THE LOGISTICAL ADVANTAGES}

\begin{abstract}
In contrast to the prolific literature on laboratory haemorrhagic shock research, there is near silence concerning actual clinical investigation of these pharmacologic interventions for shock. At least in terms of the initial management of the trauma victim, nothing much seems to have been added to the time honored principles of controlling haemorrhage and replacing lost blood.
\end{abstract}

$$
\text { Bellamy }{ }^{18}
$$

Traditionally, blood has not been available for far forward combat casualty care, and fluids have been used instead. The resuscitation fluid of choice in the current TCCC guidelines is Hextend which contains 6\% HES $(670 / 0.7)$ in lactated Ringers, and the guideline procedure is as follows: If a field combatant suffers significant blood loss, and has a weak or absent palpable peripheral pulse and/or altered mental status (without head injury), the medic should: (1) minimise or eliminate the imminent threat, (2) stop the bleeding and (3) gain intravenous or intraosseous access and administer $500 \mathrm{~mL}$ of Hextend. ${ }^{15}$ If there is no response after $30 \mathrm{~min}$, an additional $500 \mathrm{~mL}$ is recommended but no more as volumes greater than $10 \mathrm{~mL} / \mathrm{kg}$ have been linked to coagulopathic bleeding. ${ }^{6} 17$ 


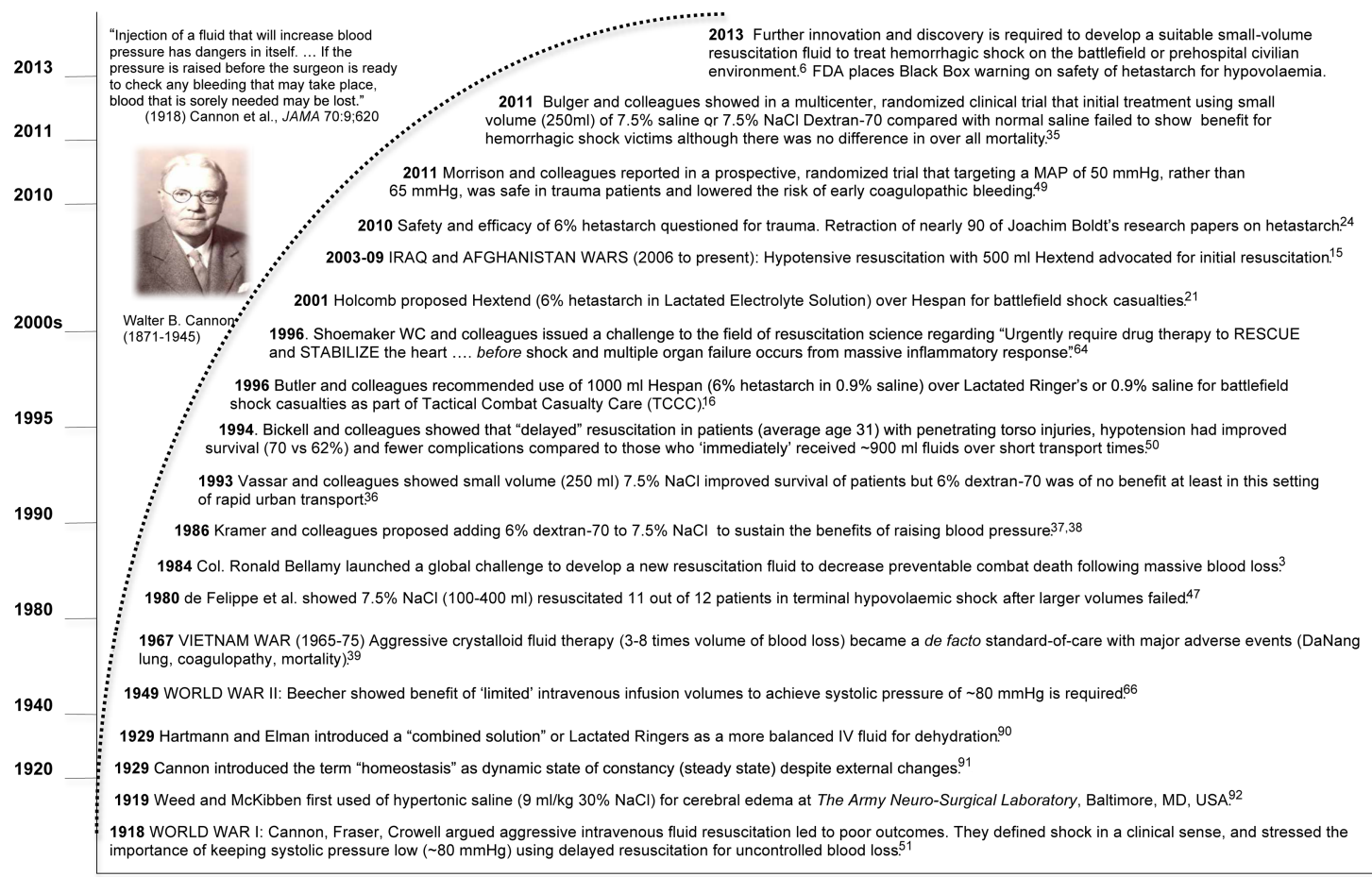

Figure 1 A brief history of small-volume fluid resuscitation for traumatic haemorrhagic shock.

The military adoption of Hextend for initial battlefield resuscitation was based on a careful compromise among need, cube weight and efficacy. ${ }^{21} 17$ HES is a colloidal plasma expander and comes in many different molecular weights and

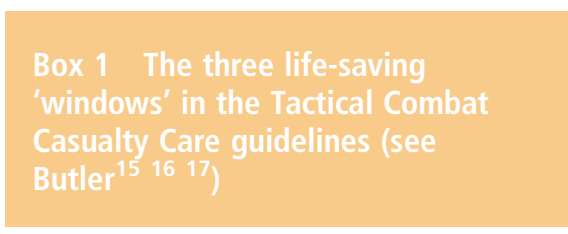

- Care under fire' refers to care rendered at the scene, and is limited to those treatments carried out by the combat medic, and often a surgeon in the case of special operation teams. This window is called the Platinum 5 to $10 \mathrm{~min}$.

- Tactical field care' is the care rendered once the casualty and/or the unit is no longer under hostile fire or imminent threat. Medical treatment is still limited by time and space and encompasses the Golden Hour.

- Combat casualty evacuation care' is the care rendered while the casualty is being evacuated which may take a number of hours until more definitive surgical care and triage are available. molar substitutions. When injected intravenous or intraosseous, HES in lactated Ringers draws fluid from the extravascular space into the blood, raises mean arterial pressure (MAP), and generally has a longer intravascular presence than normal saline or lactated Ringers alone. ${ }^{22} 23$ Thus, colloids may be beneficial for delayed evacuation times since $1 \mathrm{~L}$ of $6 \%$ HES intravascularly is equivalent to about $6 \mathrm{~L}$ of lactated Ringers meaning that a field medic could carry less weight with more life-saving potential. On 8-9 January 2010, the US Army Institute of Surgical Research at Fort Sam hosted a review of TCCC procedures and concluded that no changes to the current hypotensive resuscitation protocols using Hextend strategy were indicated, but encouraged further research and trials using freeze-dried plasma, platelets, oxygen carriers, red blood cells and haemoglobin substitutes for battlefield resuscitation. ${ }^{6}$

\section{RETHINKING THE HES STRATEGY: THE GOOD, BAD AND THE UNKNOWN'}

In 2010, the same year the US military endorsed the continued use of Hextend, the world of intravenous fluid management was shaken to read the news that Dr Joachim Boldt, a leading German anaesthesiologist and proponent of HES, was accused of misrepresenting his clinical trial data. ${ }^{24}$ On further investigation, Boldt was fired from Klinikum Ludwigshafen and nearly 90 of his refereed publications were retracted from 11 leading journals by a consortium of editors. This development had important military considerations because many of Boldt's studies formed the basis of clinical guidelines for HES fluid therapy worldwide. During a period of 10 years when Boldt and colleagues were claiming clinical safety and efficacy of HES, ${ }^{25} 26$ an increasing number of animal and clinical studies were showing adverse events including increased risk for bleeding, heart and kidney failure, shock and death. ${ }^{1327} 28$

Among the key studies reporting adverse effects of HES is a retrospective analysis of 2225 critically ill trauma patients by Lissauer and colleagues at the University of Maryland Medical Center. ${ }^{29}$ The authors concluded that in those patients who received 6\% HES there was significantly higher renal dysfunction and death. Béchir and colleagues also cautioned against the use of a second generation 10\% HES (HES 200/0.5) in humans, as they found it was associated with fatal outcomes within the first $24 \mathrm{~h}$ after severe burn injury. ${ }^{30}$ Hartog and colleagues further questioned the use of a third generation HES (Voluven; HES 130/ 0.4 ) after analysis of 56 randomised trials, 
and they concluded that safety has not been adequately addressed. ${ }^{28}$ In 2012, Perner et al conducted a 798 patient study comparing the effects of Voluven with Ringers-acetate in sepsis patients and showed that HES was associated with an increase in absolute risk of death (number needed to harm=13). ${ }^{31}$ Of military significance, Ogilvie and coworkers examined the effect of 500-1000 mL Hextend on 1714 patients (805 received Hextend), volumes similar to what is currently recommended in the TCCC guidelines and at their Level 1 trauma centre in Florida. ${ }^{32}$ The group concluded that initial resuscitation with 6\% HES was associated with reduced mortality and no obvious coagulopathy. Unfortunately, there were a number of limitations of this study: (1) the study was not blinded or randomised; (2) the Hextend group had significantly more intensive care unit admissions (41\% vs $35 \%)$ with a larger number of blood transfusions $(34 \%$ vs $20 \%)$, plasma transfusions (20\% vs $12 \%)$, and significantly higher rates of septic shock and acute respiratory disease syndrome; and (3) the fluid was administered within $2 \mathrm{~h}$ of hospital admission and not immediately on site, as would be mandatory on the battlefield.

On 24 June 2013, after examining the growing number of experimental studies and large randomised trials cautioning HES use, the US Federal Drug Administration issued 'a box warning' and concluded that HES solutions should not be used to treat hypovolemic patients, the critically ill (eg, those with sepsis) or those patients undergoing cardiac surgery. ${ }^{33}$ In the same month, the European Medicines Agency formally suggested that HES be banned altogether. Whether these new developments will impact on the safety and efficacy of Hextend's use for initial resuscitation according to the TCCC guidelines on the battlefield remains unknown.

\section{BATTLEFIELD RESUSCITATION: WHAT ARE WE MISSING?}

While the widespread training of medics in tactical combat casualty care (TCCC) has clearly saved lives, the use of saline and colloid starch by medics on the battlefield does not represent a significant technological advance in ability since saline was first used for resuscitation in 1831.

\section{Blackbourne and colleagues ${ }^{34}$}

This 2010 pronouncement by key opinion leaders was alarming but not surprising. The resuscitation field (military or civilian) has had little or no evidencebased fluid innovation for over 100 years. Animal models using saline fluids with or without pharmacological 'adjuncts' such as calcium-channel blockers, ATP-pathway modifiers, prostaglandins, pyruvate, $\mathrm{Na}^{+} /$ $\mathrm{H}^{+}$exchange inhibitors, pentoxifylline, dihydroepiandrosterone, phosphodiesterase inhibitors or a variety of colloids (HES, dextran-70, gelatins) have all had limited success in translation to humans. ${ }^{35-43}$ However, two adjuncts, valproic acid and $17 \quad \beta$-oestradiol, have shown a number of promising clinically-relevant attributes, such as cardiovascular support, blunting the inflammatory response and multiple organ protection, and further translational studies are required. ${ }^{44}$

In addition to finding a suitable 'adjunct(s)', the other piece of the puzzle is finding a suitable vehicle in which to deliver the drug(s). Both drug(s) and vehicle must be therapeutic and not 'shock' the body a second time. In clinical practice, large-volume resuscitation using lactated Ringers or normal saline solutions are commonplace, but smaller volume vehicles such as hypertonic saline solutions may be more beneficial. ${ }^{6} 74546$ Interest in small-volume hypertonic saline solutions began in the 1980s after De Felippe and colleagues showed that 7.5\% $\mathrm{NaCl}(100-400 \mathrm{~mL})$ resuscitated 11 out of 12 patients in terminal hypovolaemic shock after larger volumes of isotonic crystalloids had failed ${ }^{37} 3847$ (Figure 1). In 1993, Vassar and colleagues in a multicentre trial showed small volume $(250 \mathrm{~mL}) 7.5 \% \mathrm{NaCl}$ improved survival of patients but the addition of $6 \%$ dextran-70 was of no further benefit in the setting of rapid urban transport. ${ }^{36}$ In animal models, $7.5 \% \mathrm{NaCl}$ has been shown to rapidly expand plasma volume but for longer term 'pressor' effect requires a suitable colloidal agent. ${ }^{37}$ Hypertonic saline also appears to have positive immunomodulatory properties, improve the microcirculation and oxygen delivery, and significantly reduce intracranial hypertension following traumatic brain injury (TBI). ${ }^{48}$ Unfortunately, $7.5 \%$ $\mathrm{NaCl}$ solution, with or without a colloid, has not translated into clinical practice, ${ }^{35}$ although the small-volume hypothesis remains attractive for the concept of permissive hypotension, and with the overall scheme of damage control resuscitation in the pre-hospital setting. ${ }^{48}$

In summary, there is a growing clinical consensus that there should be less emphasis on aggressive larger volume fluid replacement after haemorrhagic shock, as was common in the Vietnam war (Figure 1), and more emphasis on goaldirected, small-volume therapies that nurture the critically wounded slowly back to health, not create more harm. New resuscitation strategies should be developed on the lines of the Chinese proverb: 'It is better to take many small steps in the right direction than to make a great leap forward only to stumble backward'. Unfortunately, many current fluids may negatively impact on the outcome. Slow restoration of homeostatic balance in the pre-hospital environment requires small volumes and small steps to support the restorative steady-state prior to evacuation.

\section{WHAT IS THE SOLUTION?}

The properties of an 'ideal' fluid for the initial treatment of haemorrhagic shock are summarised in Box 2.

First and foremost, the new fluid should rescue and stabilise the

Box 2 A new fluid for far forware battlefield resuscitation should fulfil the following requirements after minimising or eliminating the imminent threat and stopping the bleeding

- Be easy to administer (intravenous or intraosseous, nano-sized drug delivery).

- Have a low cube weight to maximise benefit to casualty ratio. ${ }^{15}$

- Be stable in different environments. ${ }^{18}$

- Smallest volume possible to rescue the heart and gently raise mean arterial pressure into a permissive range and restore tissue perfusion without causing re-bleeding. ${ }^{49-53}$

- Prevent secondary brain injury at these hypotensive pressures.

- Blunt the ongoing untoward effects of catecholamines, and possibly the renin system, on cardiovascular, mesenteric (gastrointenstinal) and metabolic deterioration to reduce likelihood of organ failure and sepsis. $^{54-56}$

- Minimise the development of secondary brain injury. ${ }^{57-60}$

- Reduce whole body $\mathrm{O}_{2}$ metabolism, if possible.

- Slowly restore acid-base balance.

- Blunt the inflammatory cascade.

- Correct acute traumatic coagulopathy. 6162

- Be suitable for burn resuscitation and possibly pain management. ${ }^{63}$ 
cardiovascular system and neural circuitry within the brainstem to provide sufficient end-organ perfusion for brain, lung and vital organs. The heart is the key target because it is the pressure generator, the vascular system is the pressure (and flow) regulator, and the brainstem is the integrator of both (Figure 2). Outside placing the whole body into a state of therapeutic suspended animation, if the heart and vascular reactivity cannot be rescued, death will be imminent. Surprisingly, there has been limited success in rescuing the heart or brain despite the plea by Shoemaker et al in 1996 for new ways 'to prevent cardiac arrest during severe haemorrhage before control of bleeding is possible. ${ }^{64}$

\section{FIRST PILLAR OF RESUSCITATION: THE HEART (AND BRAIN)}

Restoration of MAP is lifesaving, but it must be regulated. Regulating MAP via 'permissive' hypotensive resuscitation has gained general acceptance on the battlefield. ${ }^{6}$ The term 'permissive' generally refers to the return of a palpable pulse that is required for sufficient reperfusion of the vital organs without dislodging the clot. $^{1445} 5065$ The concept can be traced back to Captain Walter B Cannon and colleagues who, in 1918, suggested the maintenance of a systolic arterial pressure of 70-80 $\mathrm{mm} \mathrm{Hg}$ to avoid losing more 'blood that is sorely needed'. ${ }^{1}$ Cannon's 'limited' fluid approach was later endorsed by $\mathrm{Lt}$
Col Henry K Beecher in the Second World War; ${ }^{66}$ however, it was not widely adopted, and the hypotensive strategy lay dormant for many decades until the early $1980 \mathrm{~s}^{36-38} 47$ and the 1994 groundbreaking prospective quasi-randomised trial of Bickell and colleagues ${ }^{50}$ (Figure 1).

The 'Bickell' trial marked the beginning of a sea change in the way hypotensive patients with penetrating truncal injuries were resuscitated, and recommended restricting pre-hospital intravenous fluids to less than $100 \mathrm{~mL} .{ }^{50}$ The most impressive findings of the study were that delayed fluid resuscitation in 289 patents led to fewer days in hospital and less mortality (30\% vs 38\%) compared with 309 patients who received immediate fluid replacement. ${ }^{67}$ In 2011, Morrison and colleagues further demonstrated in a prospective, randomised trial that targeting a MAP of $50 \mathrm{~mm} \mathrm{Hg}$ in the trauma setting, rather than $65 \mathrm{~mm} \mathrm{Hg}$, was safe, reduced transfusion requirements and lowered the risk of early coagulopathic bleeding. ${ }^{49}$ One problem with permissive hypotensive resuscitation, however, is that it is not recommended for TBI, ${ }^{57}$ and high MAP is not recommended for uncontrolled blood loss. A major innovation in TCCC and prehospital civilian resuscitation would be the development of a new small-volume fluid that could resuscitate haemorrhagic shock and treat suspected TBI at the same time. No such fluid exists.
THE SECOND PILLAR OF RESUSCITATION: VASCULAR ENDOTHELUUM

Maintaining vascular reactivity is essential to regulate MAP, and minimises regional and global ischaemia-reperfusion injury. An overlooked fact is that within seconds of delivering an intravenous fluid (or any injectable drug), the injected actives are in contact with $\sim 4000-7000 \mathrm{~m}^{2}$ of vascular endothelium, the approximate area of a football field ${ }^{68}$ (Figure 2). This vast endothelial surface, which lies between the blood and the tissues, is a master regulator of vascular tone, inflammation and coagulation, as well as a regulator of mass transport (cells, water, fuels, nutrients and ions), blood fluidity, lymphatic function, and the maintenance and growth of new blood vessels. ${ }^{69}$

\section{Preventing loss of vascular tone and cardiovascular collapse}

A longstanding observation in patients who die from traumatic haemorrhage is that the terminal event is marked by a loss of vascular endothelial reactivity or 'vasoplegia'? Vascular function is regulated by central, peripheral and local factors including the sympathetic nervous system, nitric oxide, reactive oxygen species, endothelin and the renin-angiotensin system. ${ }^{70}{ }^{71} \mathrm{~A}$ resuscitation fluid that protects the vascular endothelium may improve clinical outcomes. Since changes in the membrane potential of

\section{Two Pillars of Ultra-Small Volume Fluid Resuscitation for Severe to Catastrophic Blood Loss}

1) Heart $=$ Pressure Generator

Permissive Hypotensive Resuscitation $\uparrow$ MAP to $-50 \mathrm{mmHg}$ (palpable carotid pulse $>00 \mathrm{mmHg}$ )

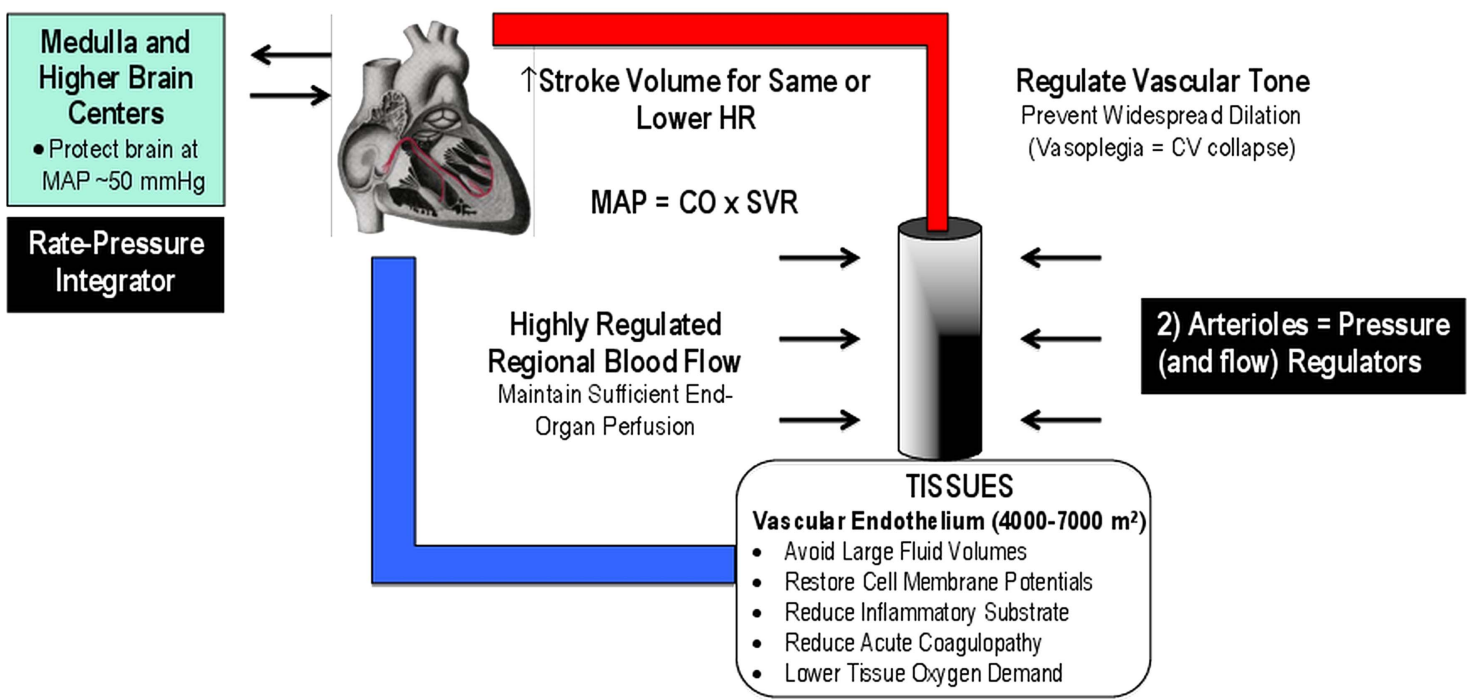

Figure 2 The two pillars of far forward resuscitation following severe to catastrophic blood loss are the heart and vascular endothelium. CO, cardiac output; SVR, systemic vascular resistance; MAP, mean arterial pressure. 
vascular smooth muscle have been shown to modulate endothelium-dependent relaxation via myo-endothelial gap junctions, ${ }^{72}$ a fluid therapy that defends the cell's voltage around its normal resting potential may also help to prevent cardiovascular collapse. ${ }^{73}$ In addition, blood flow-regulating arterioles are innervated by the autonomic nervous system and respond to various stimuli and circulating hormones. ${ }^{71}$ Thus, a resuscitation fluid that protects the vasomotor centre located in the brainstem (and higher controls centres) would be imperative for optimal regulation of carotid baroreceptor sensitivity, vascular resistance and multi-organ function.

\section{Neutrophil-endothelium interactions: function and dysfunction}

A fluid that attenuates the systemic inflammatory response would also be of significant clinical benefit (Box 2). Haemorrhagic shock leads to ischaemiareperfusion injury, inflammation, coagulopathy, metabolic acidosis, hypothermia, multi-organ dysfunction and, if not treated, death. The inflammatory response occurs from mobilisation and activation of blood borne neutrophils (and other immune cells such as lymphocytes) along post-capillary venules of hypoperfused 'inflamed' ischaemic tissues (Figure 3). Upon entry, these killer cells loaded with their toxic weapons are a two-edged sword; they are vital for protecting against infectious agents as part of innate immunity, ${ }^{74}$ yet they can inflict devastating organ damage following ischaemia- reperfusion. ${ }^{75}$ Even short periods of lowor no-flow ischaemia can trigger complex signalling cascades resulting in a neutrophil-based (and lymphocyte) inflammatory attack and coagulopathy. ${ }^{76}$

Although the mechanisms of an inflammatory attack are not fully understood, multiple targets for the 'ideal' resuscitation fluid may include the capturing, priming, docking and entry of neutrophils during ischaemia-reperfusion injury (Figure 3). Some of the endothelial-neutrophil inflammatory signalling proteins include the selectins, integrins, chemoattractants and cytokines (chemokines) such as interleukin (IL)-1, TNF- $\alpha$, IL-6 and IL-17, ${ }^{77} 78$ and other signalling mediators such as platelet/endothelial cell adhesion molecules (eg, molecule-1 and CD99) and perhaps red cells. ${ }^{79}$ Targeting the membrane potential of the endothelial cell (and underlying tissues) may also have therapeutic benefit to reduce further collateral damage from local and systemic inflammation. ${ }^{73}$ The 'membrane polarity' hypothesis ${ }^{73}$ may have merit since Ward and colleagues ${ }^{80}$ reported that emigrated neutrophils, after adhering to ventricular myocytes, caused an immediate cell membrane depolarisation, which contributed to an inflammatory-linked generation of arrhythmias, cell injury and contractile dysfunction. ${ }^{80}$ The group further showed that holding the membrane potential around the natural 'resting' polarised state reduced cell damage from inflammatory attack ${ }^{80}$ and concluded: 'Thus maneuvers that precluded activation of the $\mathrm{Na}^{+}$ channels, for example, holding the resting membrane potential at $-80 \mathrm{mV}$ significantly increased time to cell death or prevented contracture entirely'. ${ }^{80}$ Thus, the vast vascular endothelium-smooth muscle and tissue interface appears to have untapped therapeutic potential in the field of combat and civilian pre-hospital care.

\section{NATURAL HIBERNATORS: TRANSLATION FROM CARDIAC SURGERY TO DAMAGE CONTROL RESUSCITATION}

For a large number of problems there will be some animal of choice on which it can be most conveniently studied.

August Krogh ${ }^{81}$

Natural hibernators are extraordinary animals that control biological time, although the details of how they achieve up to $98 \%$ reductions in body metabolism remain elusive. ${ }^{82}$ In 1998, one of us (GPD) employed the August Krogh principle by asking: 'Could the human heart in cardiac surgery be pharmacologically manipulated to operate more like a heart of a natural hibernator? ${ }^{82}$ The hibernator does not use high potassium to slow or temporarily stop its heart during hibernation, as is standard practice in cardiac surgery today. The objective was to arrest the human heart at more natural resting 'polarised' potentials by inhibiting the voltage-dependent $\mathrm{Na}^{+}$fast channels responsible for the phase $\mathrm{O}$ upstroke of the action potential (lidocaine), and simultaneously decrease the duration of the action

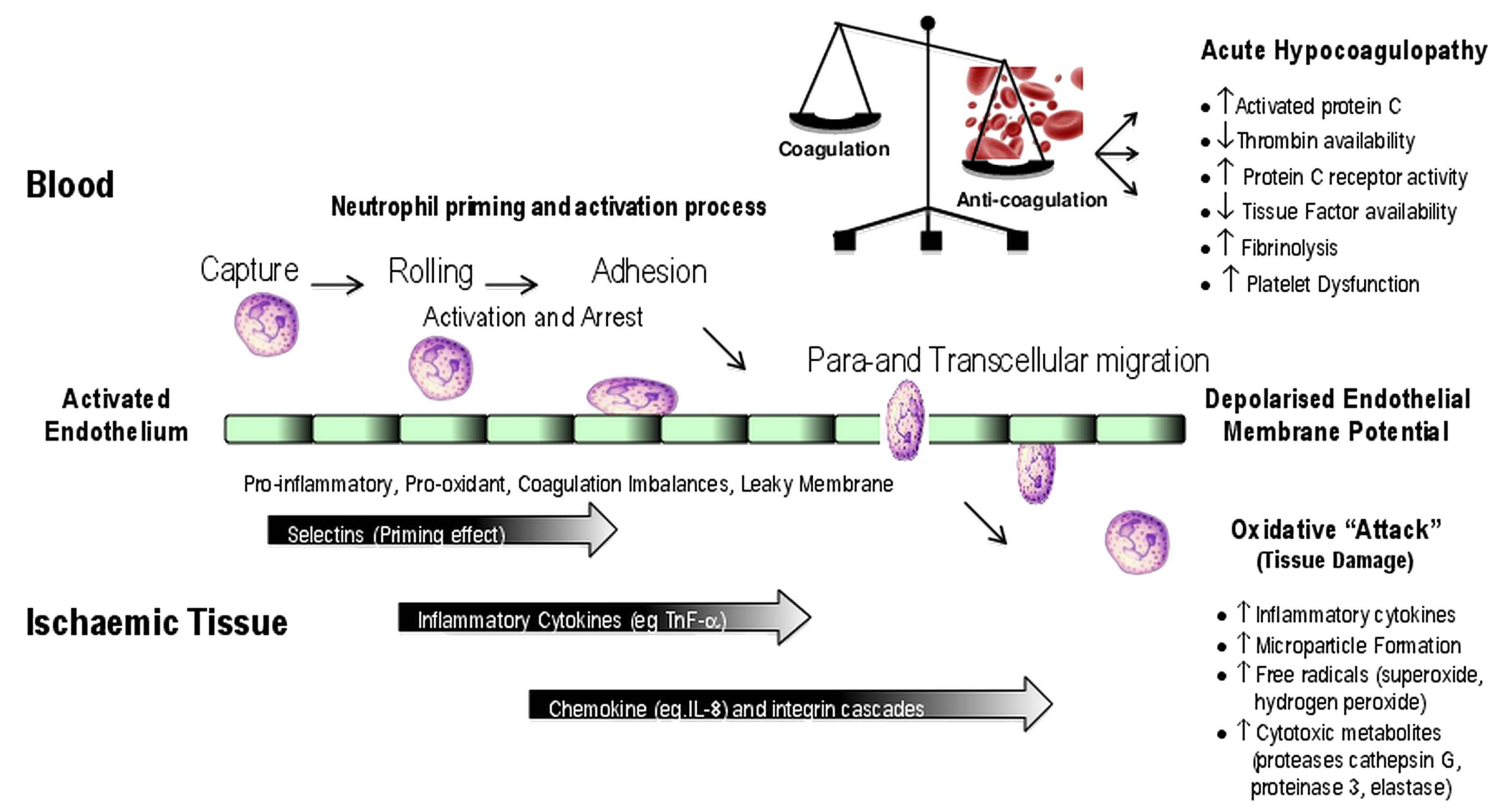

Figure 3 A broad schematic of the inflamed endothelium and coagulopathy during low flow ischaemia/hypoxia from severe haemorrhagic shock. Neutrophils are 'attracted', 'captured' or 'tethered' under the sheer force of blood flow via selectin-mediated mechanisms (P-selectins, E-selectins, and several members of the integrin superfamily, the Intercellular Adhesion Molecules) produced by the inflamed endothelium and neutrophil. ${ }^{74}$ 
potential assisted by opening $\mathrm{K}_{\mathrm{ATP}}^{+}$channels using adenosine. ${ }^{83}$ Theoretically, this strategy would 'flat-line' the heart at its resting voltage and confer protection by having fewer channels open, less $\mathrm{Na}^{2+}$ and $\mathrm{Ca}^{2+}$ loading, less inflammation, and less arrhythmias during reanimation. ${ }^{73}$ What emerged was the world's first low potassium 'polarising' adenosine and lidocaine with $\mathrm{Mg}^{2+}$ (ALM) cardioplegia, ${ }^{73}$ which was recently shown to be superior to the standard Buckberg solution in a prospective, randomised trial. ${ }^{84}$ The study showed patients receiving ALM cardioplegia had significantly lower troponins, improved post-operative cardiac function, $50 \%$ less blood transfusions, one full day less in ICU and two days less in hospital compared with the standard cardioplegia solution. ${ }^{84}$

With respect to decreasing preventable combat or civilian death following severe to massive blood loss, the key point is that ALM at high concentrations 'arrests' the heart, and at lower concentrations resuscitates and protects the heart. In an initial haemorrhagic shock study, the colloids $6 \%$ and $10 \%$ HES and $6 \%$ dextran were shown to promote cardiac instability, compromise haemodynamics and increase mortality during resuscitation in the rat model of severe $40 \%$ blood loss. ${ }^{13} 53$ In direct contrast, a second study showed that $\sim 1 \mathrm{~mL} / \mathrm{kg}$ bolus of $7.5 \% \mathrm{NaCl}-\mathrm{ALM}$ (without colloids) rescued the heart and resuscitated MAP into the hypotensive range with no deaths, ${ }^{52} 53$ and the ultra-small volume fully corrected acute traumatic coagulopathy at 60 min. ${ }^{62}$ In a third study, there was an unexpected $100 \%$ survival in small volume $7.5 \% \mathrm{NaCl}-\mathrm{ALM}$ group following $60 \%$ blood loss with improved MAP and few or no arrhythmias compared with $7.5 \% \mathrm{NaCl}$ alone and other treatment groups. ${ }^{52}$ Adenosine-lidocaine also has the advantage of displaying potent antiinflammatory properties by reducing the priming and activation of neutrophils. ${ }^{85}$

In 2012, Granfeldt and colleagues successfully translated the ALM rat experiments into a pig model of $75 \%$ blood loss. $^{86}$ A small volume $(4 \mathrm{~mL} / \mathrm{kg} \quad 7.5 \%$ $\mathrm{NaCl}-\mathrm{ALM}$ ) resuscitated the MAP into the hypotensive region with a twofold increase in stroke volume, a $34 \%$ fall in blood lactate and a $43 \%$ higher $\mathrm{O}_{2}$ delivery. ${ }^{87}$ After the shed blood was returned, whole body $\mathrm{O}_{2}$ consumption fell, systemic vascular resistance increased by $30 \%$ and urine output in the ALM group increased threefold compared with $7.5 \% \mathrm{NaCl}$ treatment. ${ }^{86}$ Importantly, small volume $7.5 \%$ $\mathrm{NaCl}$ alone was not optimal for hypotensive resuscitation in rat or pig, which is consistent with the recent randomised, multicentre trial that reported no significant benefit of $250 \mathrm{~mL} 7.5 \% \mathrm{NaCl}$ or $7.5 \%$ $\mathrm{NaCl} \quad 6 \%$ Dextran-70 compared with normal saline for early resuscitation of haemorrhagic shock ${ }^{35}$ (Figure 1). Last, the cardiac rescue potential of small volume $7.5 \% \mathrm{NaCl}-\mathrm{ALM}$ was further demonstrated by Granfeldt et al who showed that a $20 \mathrm{~mL}$ bolus of $7.5 \% \quad \mathrm{NaCl}-\mathrm{ALM}$ $(0.5 \mathrm{~mL} / \mathrm{kg})$ significantly reduced fluid requirement by $40 \%$ to reach a target MAP of $50 \mathrm{~mm} \mathrm{Hg}$ in pig model following $75 \%$ blood loss, ${ }^{88}$ and a $10 \mathrm{~mL}$ bolus injection of $0.9 \% \mathrm{NaCl}-\mathrm{AL}$ (no $\mathrm{Mg}^{2+}$ ) with return of shed blood led to a significant $27 \%$ drop in whole body $\mathrm{O}_{2}$ consumption and improved cardiac and renal function. ${ }^{88}$ More recently, ALM rescued the haemodynamics and corrected coagulopathy, including clot retraction, following $8 \mathrm{~min}$ of asphyxial hypoxia in rats. ${ }^{89}$

On the battlefield, we envisage a smallvolume bolus of hypertonic saline ALM as an initial resuscitation strategy followed by an ALM saline infusion for evacuation; a one-two delivery method for damage control resuscitation. Although the ALM strategy has shown experimental promising results to date, we are mindful of the long list of drugs that have failed to translate into humans after showing compelling superiority in animal models. Further research is required to establish if we have raised the bar to meet the 1984 Bellamy challenge for battlefield resuscitation, ${ }^{3}$ and if the innovation represents 'a significant technological advance in ability since saline was first used for resuscitation in 1831'.34

Contributors All authors contributed equally to the planning and writing of the manuscript. GPD takes full responsibility for its overall content and presentation.

Competing interests GPD is the inventor of the ALM technology for cardiac surgery, organ preservation, infection and trauma. GPD currently has no commercial interest in the ALM technology. DT and HL have no conflicts of interest.

Disclaimer The opinions and assertions contained herein are the private views of the authors, and are not to be construed as official or reflecting the views of the US Navy, Military or Department of Defense.

Provenance and peer review Not commissioned; externally peer reviewed.

To cite Dobson GP, Letson HL, Tadaki D. J R Army Med Corps 2014;160:9-15.

Received 8 July 2013

Revised 30 August 2013

Accepted 6 September 2013

J R Army Med Corps 2014;160:9-15. doi:10.1136/jramc-2013-000145

\section{REFERENCES}

1 Beekley AC. Damage Control Resuscitation: a sensible approach to the exsanguating patient. Crit Care Med 2008:36(No 7 Supp):S267-274.
2 Martin GJ, Dunne JR, Cho JM, et al. Prevention of infections associated with combat-related thoracic and abdominal cavity injuries. J Trauma 2011;71(2 Suppl 2):S270-281.

3 Bellamy RF. The causes of death in conventional land warfare: implications for combat casualty care research. Mil Med 1984;149:55-62.

4 WHO. Injuries \& violence: the facts. Geneva, 2010.

5 Angele MK, Schneider CP, Chaudry IH. Bench-to-bedside review: latest results in haemorrhagic shock. Crit Care 2008;12:218

6 McSwain NE, Champion HR, Fabian TC, et al. State of the Art of Fluid Resuscitation 2010: prehospital and immediate transition to the hospital. I Trauma 2011;70(5 Suppl):S2-10.

7 Dutton RP. Resuscitative strategies to maintain homeostasis during damage control surgery. $\mathrm{Br} J$ Surg 2012;99(Suppl 1):21-8.

8 Wiggers CJ. The Prognostic Significance of Pulse Pressure Changes During Haemorrhage. Arch Int Med 1910;6(Sept):281-92.

9 Frost P, Wise M. Recognition and management of the patient with shock. Acute Med 2006;5:43-7.

10 Hoyt DB. A clinical review of bleeding dilemmas in trauma. Semin Hematol 2004:41:40-3.

11 Soreide E, Deakin CD. Pre-hospital fluid therapy in the critically injured patient-a clinical update. Injury 2005;36:1001-10.

12 Spinella PC, Holcomb JB. Resuscitation and transfusion principles for traumatic haemorrhagic shock. Blood Rev 2009;23:231-40.

13 Letson HL, Dobson GP. Small-volume 7.5\% NaC with $6 \%$ Dextran-70 or $6 \%$ and $10 \%$ Hetastarch are associated with arrhythmias and death following $60 \mathrm{~min}$ of severe haemorrhagic shock in the rat in vivo. J Trauma 2011;70(June 6):1444-52.

14 Jackson K, Nolan J. The role of hypotensive resuscitation in the management of trauma. J Intensive Care Soc 2009:10:109-14.

15 Butler FK. Fluid resuscitation in tactical combat casualty care: brief history and current status. J Trauma 2011;70:S11-12.

16 Butler F, Hagmann J, Butler EG. Tactical combat casualty care in special operations military medicine. 1996:161(Suppl 3):1-16.

17 Butler FKJ, Holcomb JB, Giebner SD, et al. Tactical combat casualty care 2007: evolving concepts and battlefield experience. Mil Med 2007;172(11 Suppl.):1-19.

18 Bellamy RF, Maningas PA, Wenger BA. Current shock models and clinical correlations. Annals of Emerg Med 1986:15:1392-5.

19 Kotwal RS, Montgomery HR, Kotwal BM, et al. Eliminating preventable death on the battlefield. Arch Surg 2011;146:1350-8.

20 Gerhardt RT, Berry JA, Blackbourne LH. Analysis of life-saving interventions performed by out-of-hospital combat medical personnel. J Trauma 2011;71(1 Suppl):S109-113.

21 Holcomb JB. Fluid resuscitation in modern combat casualty care: lessons learned from Somalia. J Trauma 2003;54(5 Suppl.):S46-51.

22 Mortelmans Y, Merckx E, van Nerom C, et al. Effect of an equal volume replacement with $500 \mathrm{~mL} 6 \%$ hydroxyethyl starch on the blood and plasma volume of healthy volunteers. Eur J Anaesthesiol 1995:12:259-64.

23 Handrigan MT, Bentley TB, Oliver JD, et al. Choice of fluid influences outcome in prolonged hypotensive resuscitation after haemorrhage in awake rats. Shock 2005;23:337-43

24 Shafer SL. Editor's note: notices of retraction. Anesth Analg 2011;112:1246-7.

25 Boldt J, Priebe HJ. Intravascular volume replacement therapy with synthetic colloids: is there an influence on renal function? Anesth Analg 2003:96:376-82.

26 Boldt J, Mayer J, Brosch C, et al. Volume replacement with a balanced hydroxyethyl starch 
(HES) preparation in cardiac surgery patients. J Cardiothorac Vasc Anesth 2010;24:399-407. Retraction in: J Cardiothorac Vasc Anesth. 2011;2025(2014):2755-2017.

27 Hartog C, Reinhart K. CONTRA: Hydroxyethyl starch solutions are unsafe in critically ill patients. Intensive Care Med 2009;35:1337-42.

28 Hartog C, Kohl M, Reinhart K. A systematic review of third-generation Hydroxyethyl Starch (HES 130/0.4) in resuscitation: safety not adequately addressed. Anesth Analg 2011;112:635-45.

29 Lissauer ME, Chi A, Kramer ME, et al. Association of $6 \%$ hetastarch resuscitation with adverse outcomes in critically ill trauma patients. Am J Surg 2011;202:53-8.

30 Béchir M, Puhan MA, Neff SB, et al. Early fluid resuscitation with hyperoncotic hydroxyethyl starch 200/0.5 (10\%) in severe burn injury. Crit Care 2010;14:R123.

31 Perner $A$, Haasem N, Guttormsen $A B$, et al. Hydroxyethyl Starch 130/0.42 versus Ringer's Acetate in Severe Sepsis. New Eng J Med 2012;367:124-34.

32 Ogilvie MP, Pereira BM, McKenney MG, et al. First report on safety and efficacy of hetastarch solution for initial fluid resuscitation at a level 1 trauma center. J Am Coll Surg 2010;210:870-82.

33 http://wwwfdagov/BiologicsBloodVaccines/ SafetyAvailability/ucm358271 htm

34 Blackbourne L, Czarnik J, Mabry R, et al. Decreasing Killed in Action and Died of Wounds Rates in Combat Wounded. Editorial J Trauma 2010;69 (Supplement 1):S1-4.

35 Bulger EM. 7.5\% Saline and 7.5\% Saline/6\% Dextran for Hypovolemic Shock. J Trauma 2011;70(5 May Supplement):S27-9

36 Vassar MJ, Fischer RP, O'Brien PE, et al. A multicenter trial for resuscitation of injured patients with $7.5 \%$ sodium chloride. The effect of added dextran 70. The Multicenter Group for the Study of Hypertonic Saline in Trauma Patients. Arch Surg 1993:128:1003-11.

37 Kramer GC, Perron PR, Lindsey DC, et al. Small-volume resuscitation with hypertonic saline dextran solution. Surgery 1986;100:239-47.

38 Holcroft JW, Vassar MJ, Turner JE, et al. $3 \% \mathrm{NaCl}$ and $7.5 \% \mathrm{NaCl} /$ dextran 70 in the resuscitation of severely injured patients. Ann Surg 1987;206:279-88.

39 Alam HB, Rhee P. New developments in fluid resuscitation. Surg Clin North Am 2007;87:55-72.

40 Cotton BA. Alternative fluids for prehospital resuscitation: "Pharmacological" resuscitation fluids. J Trauma 2011;70(Suppl 5):S30-31.

41 Reinhart K, Perner A, Sprung CL, et al. Consensus statement of the ESICM task force on colloid volume therapy in critically ill patients. Intensive Care Med 2012:38:368-83.

42 Gruen RL, Brohi K, Schreiber $M$, et al. Haemorrhage control in severely injured patients. Lancet 2012;380 (Sept 22):1099-108.

43 Dubick MA. Current concepts in fluid resuscitation for prehospital care of combat casualties. US Army Med Dep J 2011;5-6:18-24.

44 Santry HP, Alam HB. Fluid Resuscitation: past, present and the future. Shock 2010;33:229-41.

45 Pepe PE, Mosesso VNJ, Falk JL. Prehospital fluid resuscitation of the patient with major trauma. Prehosp Emerg Care 2002:6:81-91.

46 Rhee P. Noncolligative properties of intravenous fluids. Curr Opin Crit Care 2010;16:317-22.

47 de Felippe JJ, Timoner J, Velasco IT, et al. Treatment of refractory hypovolaemic shock by $7.5 \%$ sodium chloride injections. Lancet 1980:2:1002-4.

48 Dubick MA, Shek P, Wade CE. ROC trials update on prehospital hypertonic saline resuscitation in the aftermath of the US-Canadian trials. Clinics 2013:68:883-6.

49 Morrison CA, Carrick MM, Norman MA, et al. Hypotensive resuscitation strategy reduces transfusion requirements and severe postoperative coagulopathy in trauma patients with haemorrhagic shock: preliminary results of a randomized controlled trial. J Trauma 2011;70:652-63.

50 Bickell WH, Wall MJJ, Pepe PE, et al. Immediate versus delayed fluid resuscitation for hypotensive patients with penetrating torso injuries. N Engl J Med 1994:331:1105-9.

51 Cannon W, Fraser J, Cowell E. The preventative treatment of wound shock. JAMA 1918;70:618-21.

52 Letson HL, Dobson GP. Unexpected 100\% Survival following 60\% Blood Loss using Small-Volume 7.5\% $\mathrm{NaCl}$ with Adenocaine and $\mathrm{Mg} 2+$ in the rat model of Extreme Haemorrhagic Shock. Shock 2011;36 6):586-94

53 Letson HL, Dobson GP. Ultra-Small IV bolus of $7.5 \%$ $\mathrm{NaCl} / \mathrm{Mg} 2+$ with adenosine and lidocaine (ALM) improves early resuscitation outcome in the rat following severe haemorrhagic shock in vivo. J Trauma 2011;71:708-19.

54 Chernow B, Roth BL. Pharmacologic manipulation of the peripheral vasculature in shock: clinical and experimental approaches. Circ Shock 1986;18:141-55

55 Dunser MW, Wenzel V, Mayr AJ, et al. Management of vasodilatory shock: defining the role of arginine vasopressin. Drugs 2003;63:237-56.

56 Reilly PM, Wilkins KB, Fuh KC, et al. The mesenteric hemodynamic response to circulatory shock: an overview. Shock 2001:15:329-43.

57 Chesnut R. Avoidance of hypotension: conditio sine qua non of successful severe head-injury management. J Trauma 1997;42(5 Suppl):4-9.

58 Manley G, Knudson MM, Morabito D, et al. Hypotension, hypoxia, and head injury: frequency, duration, and consequences. Arch Surg 2001;136:1118-23

59 Cohen MJ, Brohi K, Ganter MT, et al. Early coagulopathy after traumatic brain injury: the role of hypoperfusion and the protein C pathway. J Trauma 2007:63:1254-61.

60 Tan PG, Cincotta M, Clavisi O, et al. Review article: Prehospital fluid management in traumatic brain injury. Emerg Med Australas 2011;23:665-76.

61 Brohi K, Singh J, Heron M, et al. Acute traumatic coagulopathy. J Trauma 2003;54:1127-30.

62 Letson $\mathrm{HL}$, Pecheniuk NM, Mhango LP, et al. Reversal of Acute Coagulopathy during hypotensive resuscitation using Small-Volume $7.5 \% \mathrm{NaCl}$ with Adenocaine and $\mathrm{Mg} 2+$ in the Rat Model of Severe Haemorrhagic Shock. Crit Care Med 2012:40:2417-22

63 Lairet KF, Lairet JR, King BT, et al. Prehospital burn management in a combat zone. Prehosp Emerg Care 2012;16:273-6.

64 Shoemaker WC, Peitzman AB, Bellamy R, et al. Resuscitation from severe haemorrhage. Crit Care Med 1996;24(2 Suppl):S12-23.

65 Krausz MM. Initial resuscitation of haemorrhagic shock. World J Emerg Surg 2006;1:14-8.

66 Beecher HK. Resuscitation and Anesthesia. Anesthesiology 1946;7:644-50.

67 Yaghoubian A, Lewis RJ, Putnam B, et al. Reanalysis of prehospital intravenous fluid administration in patients with penetrating truncal injury and field hypotension. Am Surg 2007;73:1027-30.

68 Aird WC. Endothelium as an organ system. Crit Care Med 2004;32(5 Suppl):S271-279.

69 Aird WC. Spatial and temporal dynamics of the endothelium. J Thromb Haemost 2005:3: 1392-406.

70 Gómez H, Mesquida J, Hermus L, et al. Physiologic responses to severe haemorrhagic shock and the genesis of cardiovascular collapse: Can irreversibility be anticipated? J Surg Res 2012;10(10):1-12.

71 Bruno RM, Ghiadoni L, Seravalle G, et al. Sympathetic regulation of vascular function in health and disease. Front Physiol 2012:3:284-99.
72 Allen T, Iftinca M, WC. C, et al. Smooth muscle membrane potential modulates endothelium-dependent relaxation of rat basilar artery via myo-endothelial gap junctions. J Physio/ 2002;545:975-86.

73 Dobson GP. Membrane Polarity: Target for Myocardial Protection and Reduced Inflammation in Adult and pediatric Cardiothoracic Surgery (Editorial -Free Standing). J Thorac Cardiovasc Surg 2010;140:1213-7.

74 Amulic B, Cazalet C, Hayes GL, et al. Neutrophil Function: From Mechanisms to Disease. Annu Rev Immunol 2012:30:459-89.

75 Vinten-Johansen J, Jiang R, Reeves JG, et al. Inflammation, proinflammatory mediators and myocardial ischaemia-reperfusion Injury. Hematol Oncol Clin North Am 2007:21:123-45.

76 Wiel $E$, Vallet $B$, ten Cate $H$. The endothelium in intensive care. Crit Care Clin 2005;21:403-16.

77 Johnston B, Butcher EC. Chemokines in rapid leukocyte adhesion triggering and migration. Semin Immunol 2002;14:83-92.

78 Calvey CR, Toledo-Pereyra LH. Selectin inhibitors and their proposed role in ischaemia and reperfusion. J Invest Surg 2007;20:71-85.

79 Dixit N, Simon SI. Chemokines, selectins and intracellular calcium flux: temporal and spatial cues for leukocyte arrest. Front Immunol 2012;3:1-9.

80 Ward CA, Bazzazi H, Clark RB, et al. Actions of emigrated neutrophils on $\mathrm{Na}+$ and $\mathrm{K}+$ currents in rat ventricular myocytes. Prog Biophys Mol Biol 2006;90:249-69.

81 Krogh A. The Progress of Physiology. Science 1929;70:200-4.

82 Dobson GP. Organ arrest, protection and preservation: natural hibernation to cardiac surgery: a review. Comp Biochem Physiol Part B 2004;139:469-85.

83 Dobson GP, Faggian G, Onorati F, et al. Hyperkalemic cardioplegia in adult and pediatric cardiac surgery: end of an era? Front Clin Trans/ Physiol 2013;4 28):1-28

84 Onorati F, Santini F, Dandale R, et al. "Polarizing" microplegia improves cardiac cycle efficiency after CABG for unstable angina. Int I Cardiol 2013;167:2739-46.

85 Shi W, Jiang R, Dobson GP, et al. The non-depolarizing, normokalemic cardioplegia formulation adenosine-lidocaine (Adenocaine) exerts anti-neutrophil effects by synergistic actions of its components. J Thorac Cardiovasc Surg 2012;143:1167-75.

86 Letson HL, Granfeldt A, Hyldebrandt JA, et al. Rat to Pig Translation: Small-Volume $7.5 \% \mathrm{NaCl}$ Adenocaine/ $\mathrm{Mg}^{2+}$ Has Multiple Physiological Benefits During Hypotensive and Blood Resuscitation in the Porcine Model of Severe Haemorrhagic Shock. Circulation 2012;126:A177.

87 Granfeldt A, Letson HL, Hyldebrandt JA, et al Small-Volume $7.5 \% \mathrm{NaCl}$ Adenocaine/ $\mathrm{Mg}^{2+}$ Preserves Cardiac Function During Hypotensive Resuscitation in the Pig Following Severe Haemorrhagic Shock. Circulation 2012;126:A4

88 Granfeldt A, Nielsen TK, Solling C, et al. Adenocaine and $\mathrm{Mg}^{2+}$ reduces fluid requirement to maintain hypotensive resuscitation and improves cardiac and renal function in a porcine model of severe haemorrhagic shock. Crit Care Med 2012;40:3013-25

89 Djabir Y, Letson HL, Dobson GP. Adenosine lidocaine and $\mathrm{Mg}^{2+}\left(\mathrm{ALM}^{\mathrm{TM}}\right)$ increases survival and corrects coagulopathy after 8 min asphyxial cardiac arrest in the rat. Shock 2013:40:222-32.

90 Hartmann AF, Elman R. The effects of loss of gastric and pancreatic secretions and the methods for restoration of normal conditions in the body. J Exp Med 1929:50:387-405.

91 Cannon WB. Organisation for physiological homeostasis. Physiol Rev 1929:9:399-431.

92 Weed LH, McKibben PS. Experimental alterations of brain bulk. Amer J Physiol 1919;48:531-55. 